\title{
Suppression of Inflammatory Responses by Black Rice Extract in RAW 264.7 Macrophage Cells via Downregulation of NF-kB and AP-1 Signaling Pathways
}

\author{
Pornngarm Limtrakul*, Supachai Yodkeeree, Pornsiri Pitchakarn, Wanisa Punfa
}

\begin{abstract}
Anthocyanin, a phenolic compound, has been reported to have an anti-inflammatory effect against lipopolysaccharide (LPS) induced changes in immune cells. However, little is known about the molecular mechanisms underlying its anti-inflammatory effects. Few research studies have concerned the anti-inflammation properties of colored rice extract as a functional material. Therefore, the purpose of this study was to examine anti-inflammatory effects of the polar fraction of black rice whole grain extracts (BR-WG-P) that features a high anthocyanin content. Our results showed that BR-WG-P significantly inhibited LPS-induced proinflammatory mediators, including production of $\mathrm{NO}$ and expression of iNOS and COX-2. In addition, secretion of pro-inflammatory cytokines including TNF- $\alpha$ and IL-6 was also significantly inhibited. Moreover, BR-WG-P and anthocyanin inhibited NF-kB and AP-1 translocation into the nucleus. BR-WG-P also decreased the phosphorylation of ERK, p38 and JNK in a dose dependent manner. These results suggested that BR-WG-P might suppress LPS-induced inflammation via the inhibition of the MAPK signaling pathway leading to decrease of NF-kB and AP-1 translocation. All of these results indicate that BR-WG-P exhibits therapeutic potential associated with the anthocyanin content in the extract for treating inflammatory diseases associated with cancer.
\end{abstract}

Keywords: Black rice - anti-inflammation - NF-kB - AP-1 - anthocyanin

Asian Pac J Cancer Prev, 16 (10), 4277-4283

\section{Introduction}

Inflammation is a protective response of a tissue to injury caused by pathogens, damaged cells, or irritants (Philip et al., 2004). Acute inflammation, the early stage of inflammation, is a rapid response to an injurious agent that activates various type of inflammatory cells, including neutrophils, macrophages, mast cells and lymphocytes to the site of injury (Coussens and Werb, 2002). When acute inflammation is obvious over a short period of time, it has a therapeutic effect. However, if inflammation occurs a long time period, the cellular response becomes a pattern of chronic inflammation. Chronic inflammation is related to various types of chronic diseases, including cancer, diabetes, cardiovascular disease, arthritis and autoimmune disease (Aggarwal, 2004). Moreover, chronic inflammation has been found to be a risk factor of most types of cancer and is involved with tumorgenesis, including tumor initiation, promotion, progression, invasion and metastasis (Coussens and Werb, 2002; Aggarwal et al., 2006; Lu et al., 2006). Therefore, methods to reduce inflammation and prevent these chronic health problems have been widely investigated.

The mechanism by which microbial pathogens including bacterial, viral, and parasitic induce inflammation can be better understood via the innate immune response (Mogensen, 2009). Lipopolysaccharide (LPS), a component within the cell wall of Gram-negative bacteria, could induce activation of monocytes and macrophages resulting in pro-inflammatory cytokine production leading to an acute inflammatory response against the pathogens (Sweet and Hume, 1996). These responses are associated with the activation of Toll like receptors (TLR) especially in subtype 4 (TLR4). The binding between LPS and TLR4 recruits the adapter protein for the activation of the NF-kB and AP-1 signaling pathway (Akira, 2003; and and J, 2012). The activation of NF-kB and AP-1 leads to the induction of the pro-inflammatory mediator expression including inducible cyclooxygenase-2 (COX2 ), inducible nitric oxide synthase (iNOS), nitric oxide (NO), interleukin-1 (IL-1), interleukin-6 (IL-6) and tumor necrotic factor alpha (TNF- $\alpha$ ) (Lawrence, 2009). Involvement of the MAPK pathway in the expression of inflammatory mediators through NF-kB and AP-1 activation has been demonstrated (Fang et al., 2004; Kim et al., 2014).

Colored rice extract especially black rice or red rice has been reported to possess an anti-oxidant capacity, anti-invasion and anti-inflammatory effect (Ichikawa et al., 2001; Min et al., 2010; Pintha et al., 2014). However, 
the molecular mechanism of the anti-inflammatory effect of black rice extract has not been reported. In the present study, black rice whole grain sample was harvested from an organic farm in Chiang Mai Province in the northern part of Thailand, and was then subjected to the extraction procedure to achieve the polar fraction (BR-WG-P) which was enriched with anthocyanin content. We next investigated the anti-inflammatory effect of the BR-WG-P against RAW 264.7 macrophage cells and found that the anthocyanin-enriched black rice extract could inhibit LPS-induced inflammation through the inhibition of the NF-kB and AP-1 signaling pathway.

\section{Materials and Methods}

\section{Chemicals and reagents}

RPMI 1640 and penicillin-streptomycin were obtained from Gibco (Grand Island, NY, USA). LPS purified from Escherichia coli and radio-immunoprecipitation assay (RIPA) lysis buffer, protease inhibitors and $\beta$-actin antibody were purchased from Sigma-Aldrich (St. Louis, MO, USA). Cytokine ELISA kits were supplied from Biolegend (USA). Antibody for PARP was purchased from Santa Cruz Biotechnology (Santa Cruz, CA, USA). Antibody for iNOS was obtained from Merck-Millipore (Darmstadt, Germany). Antibodies against COX-2, pp38, p38, pJNK, JNK, pERK, ERK, NF-kB and c-Jun were purchased from Cell Signaling Technology (Beverly, MA, USA). Nitrocellulose membrane was obtained from GE Healthcare (UK). Commasie Plus ${ }^{\mathrm{TM}}$ Protein Assay Reagent, ECL reagent and fetal bovine serum (FBS) were obtained from Thermo Scientific (USA).

\section{Plant material}

Black rice (Oryza sativa L.) was harvested in wet season from Doi Saket Organic Farm, Chiang Mai Province, Thailand. A voucher specimen number (023149) was certified by the herbarium at the Flora of Thailand, Faculty of Pharmacy, Chiang Mai University, Thailand.

\section{Preparation of $B R-W G-P$}

Briefly, one kilogram of whole grains black rice was finely ground and soaked in $50 \%$ ethanol for $24 \mathrm{~h}$. The rice samples were then filtered through filter paper to separate the residue. The filtrated samples were then evaporated using a rotary vacuum evaporator (BUCHI, Switzerland) to obtain the ethanolic fractions. The ethanolic fractions were further partitioned with saturated butanol to obtain the polar fraction of the black rice whole grains extract (BR-WG-P). The polar fraction was then evaporated and freeze-dried to obtain the black rice extract powder.

\section{Cell cultures}

The RAW 264.7 macrophage cell line was obtained from American Type Culture Collection (ATCC). The low cell binding dish was used to culture the cells (Thermo Scientific, USA). These cell lines were cultured in RPMI1640 supplemented with $10 \%$ FBS, 2 mM L-glutamine, $50 \mathrm{U} / \mathrm{mL}$ of penicillin, and $50 \mu \mathrm{g} / \mathrm{mL}$ of streptomycin. The cells were maintained in a $5 \% \mathrm{CO}_{2}$ humidified incubator at $37^{\circ} \mathrm{C}$.
Quantification of total phenolic content and phenolic compounds in BR-WG-P

Total phenolic content in BR-WG-P was determined using the modified Folin-Ciocalteu assay as previously described (Jr., 1965). Briefly, BR-WG-P (0.4 mL) was mixed with $0.3 \mathrm{~mL}$ of Folin-Ciocalteau reagent and kept in the dark at room temperature for three minutes. After that, $0.3 \mathrm{~mL}$ of sodium carbonate was added to the mixture. Then, the mixture was further incubated in a dark at room temperature for $30 \mathrm{~min}$. The absorbance of blue complex was evaluated at $765 \mathrm{~nm}$ using UV-visible spectrophotometer compared to a standard curve prepared with various concentrations of gallic acid (GA) solution. The total phenolic content was shown as milligrams of GA equivalents per gram of BR-WG-P (mg GAE/g extract).

The phenolic compounds in BR-WG-P were determined by HPLC analysis compared with standard gallic acid, protocatecheuic acid, catechin, chlorogenic acid, vanillic acid, coumaric acid and ferrulic acid. BRWG-P was dissolved in methanol and subjected to HPLC (Agilent Tecnologies, CA, USA) using reversed-phase C18 column (WATER, MA, USA). The mobile phase was composed of methanol to $0.1 \%$ trifluoroacetic acid (TFA) (1:1). The detection wave length was 280 and 325 $\mathrm{nm}$ and the flow rate was set at $1.0 \mathrm{~mL} / \mathrm{min}$. The peak area was calculated and compared with the standard to obtain the concentration of all the compounds (mg/g extract).

\section{Quantification of total flavonoid content in BR-WG-P}

Total flavonoid content was measured using the aluminium chloride $\left(\mathrm{A}_{1 \mathrm{C} 1_{3}}\right)$ colorimetric assay with slightly modified (Zhishen J, 1999). BR-WG-P (0.25 mL) was mixed with $0.125 \mathrm{~mL}$ of $5 \%$ sodium nitrite $\left(\mathrm{NaNO}_{2}\right)$ for $5 \mathrm{~min}$. After that $0.125 \mathrm{~mL}$ of $10 \% \mathrm{AlCl}_{3}$ was added into the mixture. Then one $\mathrm{mL}$ of sodium hydroxide $(\mathrm{NaOH})$ was added to the mixture and it was incubated for $15 \mathrm{~min}$ at room temperature. The solution was then mixed and the absorbance was measured at $510 \mathrm{~nm}$ compared with the standard catechin using a spectrophotometer. The total flavonoid content was expressed as mg catechin equivalents per gram extract (mg CE/g extract).

\section{Quantification of total proanthocyanidin content in BR- $W G-P$}

Total proanthocyanidin content in BR-WG-P was determined using the vanillin assay with slight modification (Herald et al., 2014). Briefly, the BR-WG-P was mixed with $0.1 \mathrm{~mL}$ of $1 \%$ vanillin in methanol $(\mathrm{w} / \mathrm{v})$. Then 0.1 $\mathrm{mL}$ of sulfuric acid $\left(\mathrm{H}_{2} \mathrm{SO}_{4}\right)$ was added and incubated for $15 \mathrm{~min}$ at $30^{\circ} \mathrm{C}$. The absorbance of the sample was measured at $490 \mathrm{~nm}$ and compared with the standard of catechin. The amount of total proanthocyanidin content was expressed as milligram catechin equivalents per gram of BR-WG-P extract (mg CE/g extract).

\section{Quantification of total anthocyanin content in BR-WG-P}

Total anthocyanin analysis was measured using a $\mathrm{pH}$ differential method (Wrolstad et al., 2005). The BR-WG-P were dissolved in $0.1 \% \mathrm{HCl}, 80 \%$ methanol an incubated for $12 \mathrm{~h}$. The two dilutions of BR-WG-P solution were 
prepared for each developing stage. The first sample $(0.25 \mathrm{~mL})$ was diluted with $1 \mathrm{~mL}$ of $0.025 \mathrm{M}$ potassium chloride $(\mathrm{KCl})$ buffer $\mathrm{pH} 1.0$ and the second was diluted with $1 \mathrm{~mL}$ of $0.45 \mathrm{M}$ sodium acetate $\left(\mathrm{CH}_{3} \mathrm{COONa}\right)$ buffer $\mathrm{pH}$ 4.5. The samples were incubated at room temperature for $15 \mathrm{~min}$. The absorbance of the sample was measured at 520 and $700 \mathrm{~nm}$ using UV-visible spectrophotometer. The total anthocyanin content in the extract was expressed as cyanidin-3-glucoside, which was the most sufficient anthocyanin component. Total anthocyanin content was calculated using the following formula:

Total anthocyanin content $=\underline{\mathrm{A} \times \mathrm{Mw} \times \mathrm{DF} \times 103}$ $\varepsilon \times 1$

$\mathrm{A}=\left(\mathrm{A}_{520 \mathrm{~nm}}-\mathrm{A}_{700 \mathrm{~nm}}\right) \mathrm{pH} 1.0-\left(\mathrm{A}_{520 \mathrm{~nm}}-\mathrm{A}_{700 \mathrm{~nm}}\right) \mathrm{pH} 4.5$ $\mathrm{MW}=$ Molecular weight of cyanidin-3-glucoside $\mathrm{DF}=$ Dilution Factor

$\varepsilon=$ Molar extinction coefficient $=\mathrm{L} \mathrm{x} \mathrm{mol}^{-1} \mathrm{x} \mathrm{cm}^{-1}$ $\mathrm{L}=$ Cell path length $(1 \mathrm{~cm})$

\section{Determination of Nitric oxide (NO) production}

Nitric oxide production was determined by the detection of the nitrite concentration in cultured medium using the Griess reagent system (Sun et al., 2003). The RAW 264.7 macrophage cells were seeded in a sixwell plate at a density of $5.0 \times 10^{5}$ cells/well for $24 \mathrm{~h}$. Then the cells were pre-treated with or without various concentrations of BR-WG-P $(0-150 \mu \mathrm{g} / \mathrm{mL})$ for $2 \mathrm{~h}$. After that the cells were further incubated with or without LPS $(1 \mu \mathrm{g} / \mathrm{mL})$ for 24 hours and the cultured medium was collected for Griess reaction for the determination of nitrite production. The absorbance was measured at 540 $\mathrm{nm}$ using a microplate reader. The nitrite concentration in the cultured medium was calculated and compared with a standard curve of sodium nitrite $\left(\mathrm{NaNO}_{2}\right)$.

\section{Determination of IL-6 and TNF- $\alpha$ secretion}

The secretions of interluekin-6 (IL-6) and tumor necrotic factor-alpha (TNF- $\alpha$ ) in cultured medium were determined by an ELISA kit (Biolegend, USA) according to the manufacturer's instructions. The RAW 264.7 macrophage cells were seeded in a six-well plate at a density of $5.0 \times 10^{5}$ cells/well for $24 \mathrm{~h}$. Then the cells were co-treated with or without various concentrations of BR-WG-P $(0-150 \mu \mathrm{g} / \mathrm{mL})$ and LPS $(1 \mu \mathrm{g} / \mathrm{mL})$ for 24 $\mathrm{h}$. The cultured medium was collected for ELISA and the absorbance was measured at 450 and $570 \mathrm{~nm}$ using a microplate reader. The IL- 6 and TNF- $\alpha$ secretion in the cultured medium was calculated and compared with a standard curve of IL- 6 and TNF- $\alpha$.

\section{Immunoblot analysis}

The cultured RAW 264.7 cells were extracted with a RIPA buffer containing protease inhibitors and were then subjected to $10 \%$ SDS-PAGE. The proteins were transferred onto nitrocellulose membranes. The membranes were blocked with $5 \%$ non-fat dried-milk proteins in $0.1 \%$ TBS-tween, then probed with COX-2, iNOS, pp38, p38, pJNK, JNK, pERK, ERK, NF-kB or c-Jun. After washing with $0.3 \%$ TBS-tween, membranes were incubated with HRP-conjugated anti-mouse or anti-rabbit IgG antibody. The HRP signal was detected using an enhanced chemiluminescence (ECL) system. Equal protein loading was confirmed by each membrane, which was stripped and reprobed with anti- $\beta$-actin or PARP antibody.

\section{Statistical analysis}

All data are presented as the mean \pm standard deviation (S.D.) values. Statistical analysis was analyzed by Prism version 6.0 software using one-way ANOVA, Dunnett's test or Tukey's multiple comparison test. Statistical significance was determined at $* \mathrm{p}<0.05, * * \mathrm{p}<0.01$ or $* * * * \mathrm{p}<0.0001$.

\section{Results}

\section{Phytochemical Characterization in BR-WG-P}

After the extraction process, the BR-WG-P was weighed and further used for phytochemical and biological analysis. The percentage of yield of BR-WG-P was 0.307 calculated from one $\mathrm{kg}$ of raw material. The phytochemical characterization in BR-WG-P including, total phenolic content, phenolic compound, total flavonoid content, total anthocyanin content, and total proanthocyanidin content were determined (Table 1). The total phenolic content in the extract was $117.6 \pm 14.6 \mathrm{mg} \mathrm{GAE} / \mathrm{g}$ extract. Phenolic acid, one of members in phenolic group, contains the two subgroups including hydroxybenzoic acid and hydroxycinnamic acid. The hydroxybenzoic acid derivatives including, vanillic acid and protocatechuic acid, were found to be $4.2 \pm 0.4$ and $2.3 \pm 0.1 \mathrm{mg} / \mathrm{g}$ extract, respectively whereas gallic acid was not found to be present in BR-WG-P. The hydroxycinnamic acid derivatives including, coumaric acid, Ferulic acid, and chlorogenic acid, were detected $0.5 \pm 0.2,1.4 \pm 0.0$, and $1.7 \pm 0.3 \mathrm{mg} / \mathrm{g}$ extract, respectively. In terms of the flavonoid content determination, the aluminium chloride $\left(\mathrm{A}_{1 \mathrm{C}} 1_{3}\right)$ colorimetric assay was applied. The flavonoid content was $42.9 \pm 2.1 \mathrm{mg} \mathrm{CE} / \mathrm{g}$ extract. The anthocyanin content was found to be $8.1 \pm 1.9 \mathrm{mg} \mathrm{C}-3-\mathrm{G} / \mathrm{g}$ extract. Additionally, the flavonol derivatives, such as catechin and proanthocyanidin, were not found in BR-WG-P.

\section{Effect of BR-WG-P on NO Production in LPS-induced} RAW Macrophage Cells

Table 1. The Content of Phenolic Compounds in Black Rice whole Grain Extract (BR-WG-P)

\begin{tabular}{lc}
\hline Compounds (mg/g extract) & BR-WG-P \\
\hline Total phenolic content & $117.6 \pm 14.6$ \\
Vanillic acid & $4.2 \pm 0.4$ \\
Protocatechuic acid & $2.3 \pm 0.1$ \\
Gallic acid & $\mathrm{ND}$ \\
Coumaric acid & $0.5 \pm 0.2$ \\
Ferulic acid & $1.4 \pm 0.0$ \\
Chlorogenic acid & $1.7 \pm 0.3$ \\
Total flavonoid content & $42.9 \pm 2.1$ \\
Anthocyanin & $8.1 \pm 1.9$ \\
Catechin & $\mathrm{ND}$ \\
Proanthocyanidin & $\mathrm{ND}$ \\
\hline
\end{tabular}

*Values are meann \pm S.D. $(\mathrm{n}=3), \mathrm{ND}=$ not detectable 
To evaluate the anti-inflammatory effect of BRWG-P, the NO production was then determined by the Griess reagent system (Sun et al., 2003). A non-cytotoxic dose $(0-200 \mu \mathrm{g} / \mathrm{mL})$ of BR-WG-P was measured by MTT assay and showed no growth effects in RAW macrophage cells and was later used in the next experiment (data not shown). NO production could be induced in the LPStreated RAW macrophage cells. Pretreatment of the cells with BR-WG-P dramatically decreased the LPS-induced NO production in the cells in a dose dependent manner (Figure 1A). A catalytic enzyme iNOS is involved with NO production. The expression of iNOS was upregulated in LPS-induced RAW macrophage cells. However, the expression of iNOS was significantly decreased in a dose

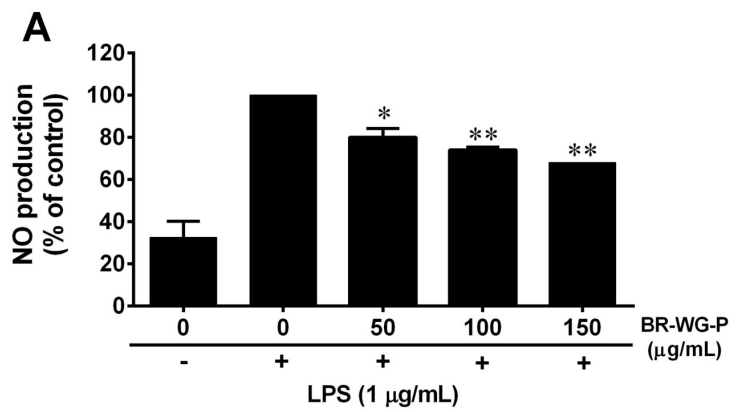

B

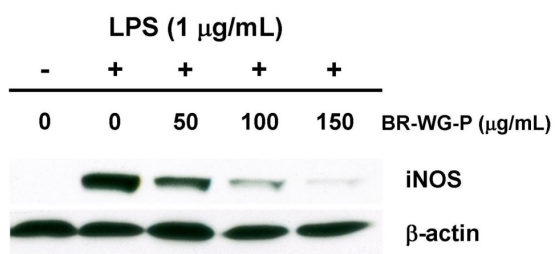

Figure 1. Nitric Oxide Production was Determined Using the Griess Reagent System. (A). The cells were pre-treated with or without various concentrations of BR-WG-P $(0-150 \mu \mathrm{g} / \mathrm{mL})$ for $2 \mathrm{~h}$ and further incubated with or without LPS $(1 \mu \mathrm{g} / \mathrm{mL})$ for $24 \mathrm{~h}$. The nitrite production in the cultured medium was measured at $540 \mathrm{~nm}$ using a microplate reader. iNOS expression was determined in RAW macrophage cells pretreated with or without BR-WG-P $(0-150 \mu \mathrm{g} / \mathrm{mL})$ and further incubated with or without LPS $(1 \mu \mathrm{g} / \mathrm{mL})$ using western blot analysis (B). All assays have been demonstrated in triplicate and the mean \pm standard deviations are shown as $* \mathrm{p}<0.05$, or $* * \mathrm{p}<0.01$ versus LPS treated RAW macrophage cells $(1 \mu \mathrm{g} / \mathrm{mL})$

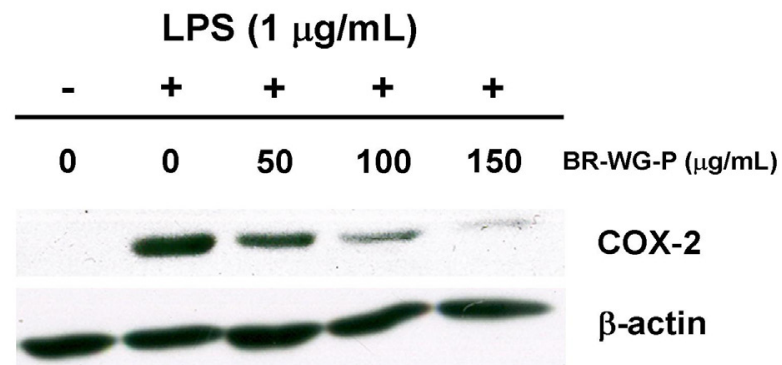

Figure 2. COX-2 Expression was Determined in RAW Macrophage Cells that were Pre-treated with or without BR-WG-P (0-150 $\mu \mathrm{g} / \mathrm{mL})$ and Further Incubated with or without LPS $(1 \mu \mathrm{g} / \mathrm{mL})$ using Western Blot Analysis. This data is representative of three independent experiments dependent manner when the cells were pretreated with BRWG-P in various concentrations $(50-150 \mu \mathrm{g} / \mathrm{mL}$ ) (Figure 1B). These results suggested that BR-WG-P extract could reduce iNOS expression leading to a decrease of NO production in LPS-induced RAW macrophage cells.

Effect of BR-WG-P on COX-2 expression in LPS-induced $R A W$ macrophage cells

Alteration of COX-2 expression and its enzymatic production, $\mathrm{PGE}_{2}$, play important roles in the development of inflammation (Ricciotti and FitzGerald, 2011). The expression of COX-2 was dramatically induced in LPS-treated RAW macrophage cells compared with the untreated cells (Figure 2). In contrast, when the cells were pretreated with various concentrations of BR-WG-P, the COX-2 expression was clearly decreased in a dose dependent manner (Figure 2). These results revealed that BR-WG-P could decrease COX-2 expression which was induced by LPS in RAW macrophage cells.

Effect of BR-WG-P on pro-inflammatory cytokine secretion in LPS-induced RAW macrophage cells

Pro-inflammatory cytokines including, IL- 6 and TNF- $\alpha$ play a key role in the inflammation cascade. These pro-inflammatory cytokine secretions were evaluated using an ELISA kit. The secretions of IL- 6 and TNF- $\alpha$ from RAW macrophage cells were induced by LPS. However, when the cells were treated with BR-WG-P the IL- 6 and TNF- $\alpha$ secretions from RAW macrophage cells were dramatically reduced in a dose dependent manner (Figure 3).

Effect of BR-WG-P on NF- $k B$ and AP-1 translocation in LPS-induced RAW macrophage cells

A

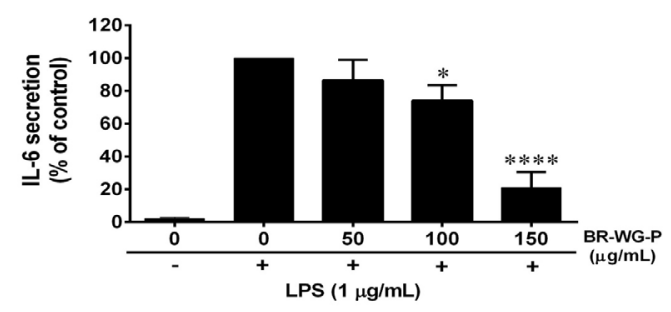

B

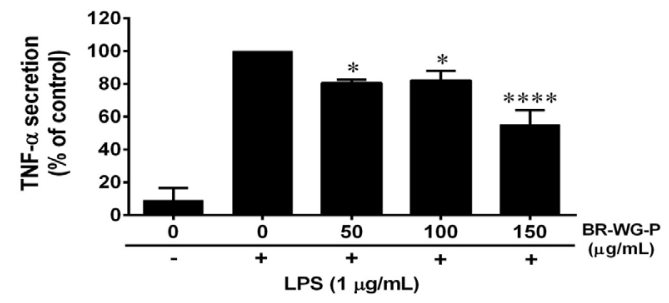

Figure 3. The IL-6 and TNF- $\alpha$ Secretion in Cultured Medium was Determined by an ELISA Kit. The RAW macrophage cells were co-treated with or without various concentration of BR-WG-P $(0-150 \mu \mathrm{g} / \mathrm{mL})$ and LPS $(1 \mu \mathrm{g} /$ $\mathrm{mL}$ ) for $24 \mathrm{~h}$. The IL-6 or TNF- $\alpha$ in the cultured medium was measured at $540 \mathrm{~nm}$ using a microplate reader. All assays have been demonstrated in triplicate and the mean \pm standard deviations are shown as $* \mathrm{p}<0.05$, or $* * * * \mathrm{p}<0.0001$ versus LPS treated RAW macrophage cells $(1 \mu \mathrm{g} / \mathrm{mL})$ 
The major transcription factors that control proinflammatory cytokine expression were NF-kB and AP-1 (Lawrence, 2009). NF-kB and AP-1 translocation were determined by the detection of NF-kB and AP-1 expression in nuclear extract using western blot analysis. LPS could induce the NF-kB and AP-1 translocation whereas the pretreatment of BR-WG-P $(150 \mu \mathrm{g} / \mathrm{mL})$ obviously decreased NF-kB and AP-1 translocation

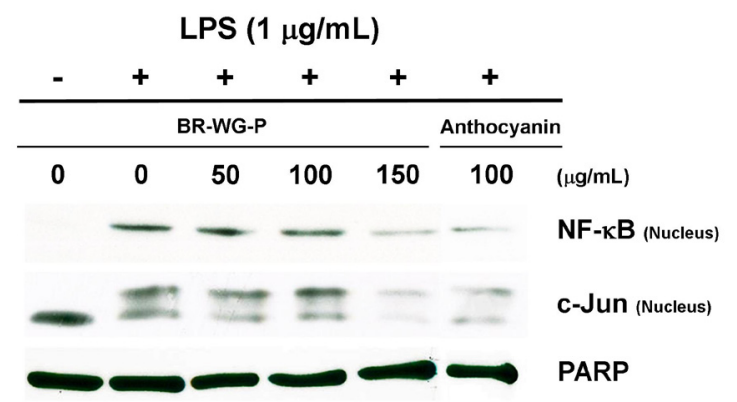

Figure 4. NF-kB and c-Jun Expression were Determined in RAW Macrophage Cells Pre-treated with or without BR-WG-P (0-150 $\mu \mathrm{g} / \mathrm{mL})$ or Anthocyanin (100 $\mu \mathrm{g} /$ $\mathrm{mL}$ ) and Further Incubated withw or without LPS (1 $\mu \mathrm{g} / \mathrm{mL}$ ) using Western Blot Analysis. This data is representative of three independent experiments

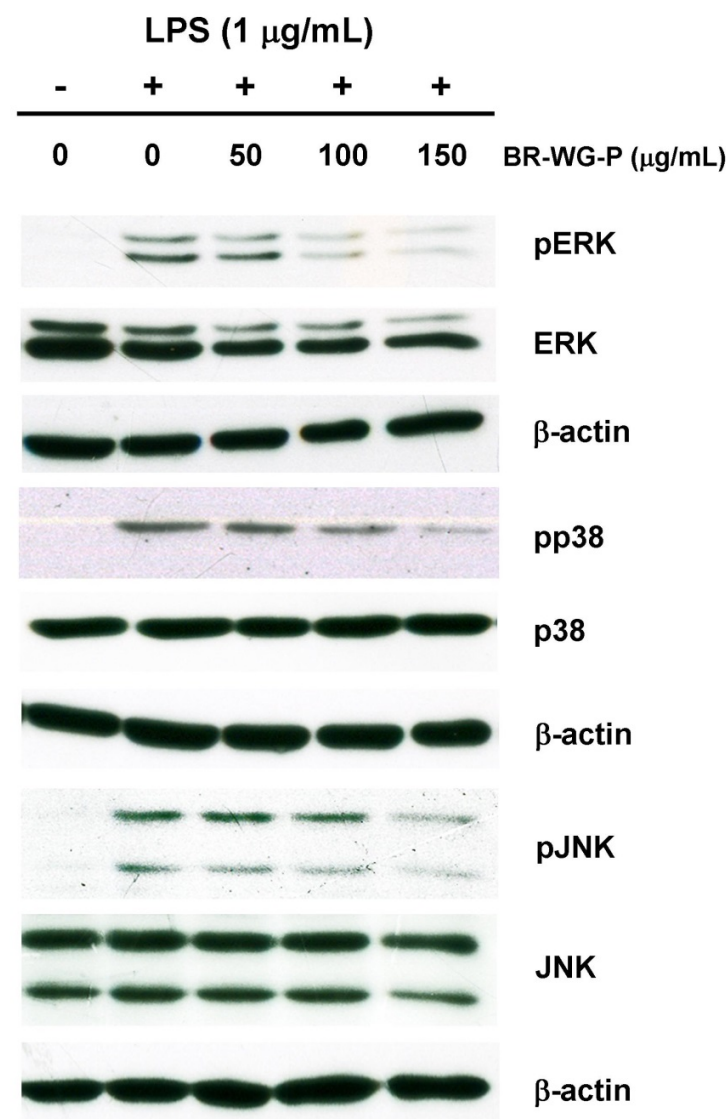

Figure 5. MAPK Related Protein Expression was Determined in RAW Macrophage Cells that were Pre-treated with or without BR-WG-P $(0-150 \mu \mathrm{g} / \mathrm{mL})$ and Further Incubated with or without LPS $(1 \mu \mathrm{g} / \mathrm{mL})$ using Western Blot Analysis. This data is representative of three independent experiments
(Figure 4). Moreover, pretreatment of the cells with anthocyanin $(100 \mu \mathrm{g} / \mathrm{mL})$ that was highly contained in BR-WG-P could significantly decrease the LPS-induced NF-kB and c-Jun (AP-1 heterodimer) translocation (Figure 4). The pretreatment of hydroxybenzoic acid $(25 \mu \mathrm{g} /$ $\mathrm{mL}$ ) also decreased the LPS-induced NF-kB and AP-1 translocation whereas vanillic acid and protocatechuic acid treatment revealed no differences in the NF-kB expression level while the expression of AP-1 was slightly decreased compared with the LPS-induced RAW macrophage cells (data not shown). These results suggested that anthocyanin and hydroxybenzoic acid which are major compounds in BR-WG-P could inhibit NF-kB and AP-1 translocation in LPS-induced RAW macrophage cells.

\section{Effect of BR-WG-P on MAPK signaling pathway}

MAPK signaling pathway is one of the signal transductions that control NF-kB and AP-1 activation (Fang et al., 2004; Kim et al., 2014). Therefore, the MAPK protein phosphorylation and expression including pERK, ERK, pp38, p38 pJNK and JNK were investigated. The level of pERK, pp38, and pJNK were significantly increased in LPS-induced RAW macrophage cells (Figure 5); while the phosphorylation of the MAPK signaling proteins was dramatically decreased in a dose dependent manner after pretreating the cells with BR-WG-P (Figure 5 ). These data revealed that BR-WG-P could inhibit MAPK (ERK, p38, and JNK) activation resulting in inhibition of NF-kB and AP-1 translocation into the nucleus.

\section{Discussion}

The anthocyanin rich fraction that was extracted from several kind of fruits and vegetables including berry, cranberry or grape exhibited antioxidant, antiproliferative, and anti-inflammatory properties (Olsson et al., 2004; Seeram et al., 2004; Yi et al., 2005). In Thailand, many people interested in the health value of colored rice such as black rice as an anthocyanin rich choice. Whole grains black rice (Oryza sativa L.) were harvested in the wet season from Doi Saket Organic Farm, Chiang Mai Province, Thailand. After that the extraction was performed using $50 \%$ ethanol and then partition with saturated butanol to obtain polar fraction of BR-WG-P. Although, BR-WG-P provided a low percentage yield $(0.307 \%)$, it contains a high phenolic content especially the flavonoids group, anthocyanin (Table 1) which plays major roles in anti-inflammatory effect (Min et al., 2010).

Pathogen induced chronic inflammation was related to an increase in NO production which is a mediator and regulator of inflammatory responses (Korhonen et al., 2005). The LPS induced RAW macrophage cells revealed an increase in NO production whereas after pre-treatment with BR-WG-P, NO production was reduced (Figure 1A). The key enzyme that regulates NO production is inducible nitric oxide synthase (iNOS) which is primarily responsible for NO production in the inflammatory processes (Zamora et al., 2000). In this study iNOS expression was dramatically increased in LPSinduced RAW macrophage cells (Figure 1B) resulting 
in an increase in NO production that was involved with the inflammatory process. Pretreatment of BR-WG-P obviously decreased the iNOS expression which lead to a reduction in $\mathrm{NO}$ production. Likewise iNOS expression, COX-2 became upregulated after being stimulated by LPS which was dramatically inhibited when the cells were pretreated with BR-WG-P (Figure 2). A reduction of COX-2 expression resulted in a decrease of prostaglandin E2 $\left(\mathrm{PGE}_{2}\right)$ production which is involved in the inflammatory process (Kalinski, 2012) by promoting local vasodilatation and induction of neutrophils, macrophages, and mast cells in the early stages of inflammation (Wang and Lau, 2006).

The pro-inflammatory cytokines, such as IL-1 $\beta$, IL-6 and TNF- $\alpha$ are significant for controlling the inflammatory process (Moller and Villiger, 2006). IL-6 not only acts as an inducer of acute phase reactions but also plays an important role in chronic inflammation (Gabay, 2006) and TNF- $\alpha$ is also significant in inflammatory disease (Bradley, 2008). Therefore, an investigation into certain natural products, particularly black rice that could reduce cytokines secretion is important. This study found that LPS induced IL- 6 and TNF- $\alpha$ secretion from RAW macrophage cells, while the secretion levels were significantly decreased when the cells were treated with BR-WG-P (Figure 3). The mechanisms that are involved in the production of pro-inflammatory mediators and cytokines including iNOS, COX-2, IL-1, IL-6 and TNF- $\alpha$ that play critical roles in inflammatory process may be controlled by the transcription factor NF-kB or AP-1 (Barnes and Karin, 1997). Stimulation occurs through the interaction between LPS and TLR4 that recruit the adaptor protein for the induction of NF-kB or AP-1 translocation into the nucleus via the activation of the mitogen-activated protein kinase (MAPK) signaling pathway (Fang et al., 2004). All of these members in MAPK including extracellular signal-regulated kinase (ERK), p38, and c-Jun NH2-terminal kinase (JNK) play a major role in the control of AP-1 activation (Kyriakis, 1999). This data is related to the previous results that showed a decrease in NF-kB and AP-1 translocation into the nucleus (Figure 4) and a reduction of the phosphorylation form of ERK, p38 and JNK after pre-treating the cells with BR-WG-P (Figure 5). Moreover, anthocyanin which is enriched in BR-WG-P may be the active compound for inhibition of NF-kB and AP-1, the key transcription factor involved with inflammation (Figure 4).

Another pathway that controls pro-inflammatory mediators and cytokines production may be involved with the IKK/NF-kB signaling pathway (Kawai and Akira, 2007). The stimulation occurs through the interaction between LPS and TLR4 and leads to the activation of the IkB kinase (IKK) complex, which induces the phosphorylation of IkB $\alpha$ leading to NF-kB translocation and activation (Akira, 2003; Hoesel and Schmid, 2013). Therefore, BR-WG-P not only inhibits the NF-kB transcription factor but also inhibits pro-inflammatory cytokine, IL-6 and TNF- $\alpha$ secretion.

These findings suggested that anthocyanin and hydroxybenzoic acid enriched BR-WG-P could inhibit NF-kB and AP-1 activation that controls the expression of pro-inflammatory mediator including iNOS, COX-2,
IL-6 and TNF- $\alpha$, leading to a decrease in the inflammatory process that is involved with chronic diseases including cancer via the inhibition of the MAPK signaling pathway.

\section{References}

Aggarwal BB (2004). Nuclear factor-kappaB: the enemy within. Cancer Cell, 6, 203-8.

Aggarwal BB, Shishodia S, Sandur SK, Pandey MK, Sethi $\mathrm{G}$ (2006). Inflammation and cancer: how hot is the link? Biochem Pharmacol, 72, 1605-21.

Akira S (2003). Toll-like receptor signaling. J Biol Chem, 278, 38105-8.

Barnes PJ, Karin M (1997). Nuclear factor-kappaB: a pivotal transcription factor in chronic inflammatory diseases. $N$ Engl J Med, 336, 1066-71.

Bradley JR (2008). TNF-mediated inflammatory disease. $J$ Pathol, 214, 149-60.

Coussens LM, Werb Z (2002). Inflammation and cancer. Nature, 420, 860-7.

Fang H, Pengal RA, Cao X, et al (2004). Lipopolysaccharideinduced macrophage inflammatory response is regulated by SHIP. J Immunol, 173, 360-6.

Gabay C (2006). Interleukin-6 and chronic inflammation. Arthritis Res Ther, 8,3 .

Herald TJ, Gadgil P, Perumal R, Bean SR, Wilson JD (2014). High-throughput micro-plate $\mathrm{HCl}$-vanillin assay for screening tannin content in sorghum grain. J Sci Food and Agriculture, 94, 2133-6.

Hoesel B, Schmid JA (2013). The complexity of NF-kappa B signaling in inflammation and cancer. Molecular Cancer, 12.

Ichikawa H, Ichiyanagi T, Xu B, et al (2001). Antioxidant Activity of Anthocyanin Extract from Purple Black Rice. $J$ Med Food, 4, 211-8.

Jr. SVLaR (1965). Colorimetry of total phenolics with phosphomolybdic-phosphotungstic acid reagents. Am J Enol Vitic, 16, 144-58

Kalinski P (2012). Regulation of immune responses by prostaglandin E2. J Immunol, 188, 21-8.

Kawai T, Akira S (2007). Signaling to NF-kappa B by Toll-like receptors. Trends in Molecular Medicine, 13, 460-9.

Kim HY, Hwang KW, Park SY (2014). Extracts of ActinidiA. arguta stems inhibited lipopolysaccharide-induced inflammatory responses through nuclear factor-kappaB pathway in Raw264.7 cells. Nutr Res, 34, 1008-16.

Korhonen R, Lahti A, Kankaanranta H, Moilanen E (2005). Nitric oxide production and signaling in inflammation. Curr Drug Targets Inflamm Allergy, 4, 471-9.

Kyriakis JM (1999). Activation of the AP-1 transcription factor by inflammatory cytokines of the TNF family. Gene Expr, 7, 217-31.

Lawrence T (2009). The nuclear factor NF-kappaB pathway in inflammation. Cold Spring Harb Perspect Biol, 1, 1651.

Lu H, Ouyang W, Huang C (2006). Inflammation, a key event in cancer development. Mol Cancer Res, 4, 221-33.

Min S-W, Ryu S-N, Kim D-H (2010). Anti-inflammatory effects of black rice, cyanidin-3-O- $\beta$-d-glycoside, and its metabolites, cyanidin and protocatechuic acid. International Immunopharmacology, 10, 959-66.

Mogensen TH (2009). Pathogen recognition and inflammatory signaling in innate immune defenses. Clin Microbiol Rev, 22, 240-73.

Moller B, Villiger PM (2006). Inhibition of IL-1, IL-6, and TNFalpha in immune-mediated inflammatory diseases. Springer Semin Immunopathol, 27, 391-408.

Olsson ME, Gustavsson KE, Andersson S, Nilsson A, Duan RD (2004). Inhibition of cancer cell proliferation in vitro by fruit 
and berry extracts and correlations with antioxidant levels. J Agric Food Chem, 52, 7264-71.

Philip M, Rowley DA, Schreiber H (2004). Inflammation as a tumor promoter in cancer induction. Seminars in Cancer Biology, 14, 433-9.

Pintha K, Yodkeeree S, Pitchakarn P, Limtrakul P (2014). Antiinvasive activity against cancer cells of phytochemicals in red jasmine rice (Oryza sativa L.). Asian Pac J Cancer Prev, 15, 4601-7.

Ricciotti E, FitzGerald GA (2011). Prostaglandins and inflammation. Arterioscler Thromb Vasc Biol,31, 986-1000.

Seeram NP, Adams LS, Hardy ML, Heber D (2004). Total cranberry extract versus its phytochemical constituents: antiproliferative and synergistic effects against human tumor cell lines. J Agric Food Chem, 52, 2512-7.

SJ, J S (2012). Total anthocyanin content and antioxidant activity of germinated colored rice. International Food Research Journal, 19, 215-21.

Sun J, Zhang XJ, Broderick M, Fein H (2003). Measurement of nitric oxide production in biological systems by using Griess Reaction assay. Sensors, 3, 276-84.

Sweet MJ, Hume DA (1996). Endotoxin signal transduction in macrophages. J Leukoc Biol, 60, 8-26.

Wang XS, Lau HYA (2006). Prostaglandin E-2 potentiates the immunologically stimulated histamine release from human peripheral blood-derived mast cells through EP1/EP3 receptors. Allergy, 61, 503-6.

Wrolstad RE, Durst RW, Lee J (2005). Tracking color and pigment changes in anthocyanin products. Trends in Food Science \& Technology, 16, 423-8.

Yi W, Fischer J, Akoh CC (2005). Study of anticancer activities of muscadine grape phenolics in vitro. J Agric Food Chem, $\mathbf{5 3}, 8804-12$.

Zamora R, Vodovotz Y, Billiar TR (2000). Inducible nitric oxide synthase and inflammatory diseases. Mol Med, 6, 347-73.

Zhishen J MT, Jianming W (1999). The determination of flavonoid contents in mulberry and their scavenging effects on Superoxide radicals. Food chem, 64, 555-9. 